This is an Accepted Manuscript of an article published by Taylor \& Francis in Music Education Research on 27 February 2019, available online: http://www.tandfonline.com/10.1080/14613808.2019.1585791.

Title: Exploring teachers' and pupils' behaviour in online and face-to-face instrumental lessons

Andrew King, Helen Prior \& Caroline Waddington-Jones 


\section{$<1>$ Abstract}

The provision of instrumental lessons in certain areas of England can be hampered by the geographical position of some schools that are rural in nature, with teachers needing to travel long distances between schools. Internet-based technologies have been successfully used elsewhere to deliver instrumental lessons. A collaboration between the authors, North Yorkshire Music Action Zone and YouCanPlay allowed the delivery of instrumental lessons using Skype in combination with a Roland VR-3EX, an AV Mixer which offers 3 camera angles and good quality sound. Our aim was to repurpose existing technology to provide instrumental lessons in remote rural communities. The study was conducted in two-phases: a pilot study in North Yorkshire; and a further roll-out of the lessons in four additional areas (Cornwall; Cumbria; Durham/Darlington; and East Riding of Yorkshire). We wished to investigate the technical challenges and pedagogical aspects of the delivery, and also compare digitally-delivered and face-to-face instrumental lessons to explore the differences in behaviour. Data collected included pre- and post-project interviews with teachers, recordings of the teachers' first and last lessons, and post-project questionnaires from pupils and their parents. Results suggested that there were technical challenges relating to sound, video and connection quality, and the physical environment of the lessons, some of which were alleviated by the Roland VR-3EX. Some concerns expressed by teachers in the initial interviews failed to materialize; others were overcome to some extent. Pupils concentrated well, were motivated to practice, and made good progress. Further analysis of the video data has allowed the comparison of face-to-face and digitally-delivered lessons. All teachers found the digital teaching more challenging than their usual face-to-face teaching; however, all reported that they would undertake similar teaching again. This paper focuses upon the 
exploring the behaviour of participants observed in the lessons. Digital delivery has the potential to provide greater access to instrumental lessons for children in rural communities.

Keywords: online learning, instrumental teaching, music, teaching behaviour.

$<1>$ Introduction

The provision of instrumental lessons in the county of North Yorkshire is hampered by its vast area and rural nature, with teachers needing to travel long distances between schools, taking time and adding costs. A pilot study that involved several primary schools was carried out to explore how technology could be harnessed to deliver peripatetic instrumental lessons online and bring music into schools with little or no provision of this area. The outcomes of this study then informed a wider study working with four additional music hubs in areas of England with similar issues concerning music delivery. The five areas that have taken part in this study have distinct rural characteristics: ${ }^{1}$

[insert table 1 here]

$<2>$ Online instrumental tuition

Online technology and methods such as video-conferencing have been used in the UK and other parts of the globe in recent decades. For example, the work of Alan Cameron in Scotland (UK) delivering instrumental lessons to remote communities using video conference facilities has been taking place for some time. This work has not been formally evaluated from a research perspective, although it has been presented at a conference (Cameron, 2010).

\footnotetext{
${ }^{11}$ https://www.cornwall.gov.uk/media/20392018/cornwall-statistics-infographica3 proof3.pdf ${ }^{1}$ http://www.countydurhampartnership.co.uk/media/12760/Sustainable-CommunityStrategy-2014---2030/pdf/SCS2014.pdf ${ }^{1}$ http://www.darlington.gov.uk/media/1187929/Section-3-Population-anddemographyREVISED.pdf ${ }^{1}$ https://www.datanorthyorkshire.org/
} 
Other instrumental tutors have been offering an online experience for specific instruments such as the Bagpipes ${ }^{2}$ which could possibly be related to both geography and access to specialist teachers, indeed this type of activity was featured in the New York Times in $2012 .^{3}$ Clearly, there is activity around delivering lessons using an online video system such as Skype and ideas around technology have been explored.

Internet-based technologies such as pre-recorded videos (YouTube) (Kruse \& Veblen, 2012; Savage, 2012; Waldron, 2012) have been explored as a means of delivering instrumental lessons. Kruse \& Veblen examined areas such as the nature of the instructional video (length, teacher discourse), the gender, age and ethnicity of the instructors, the musical content, and the teaching methods. Forty instructional videos were considered across an equal number of instrument types which were banjo, fiddle, guitar and mandolin. The researchers discovered that across the sample identified nearly all were targeted towards beginners and teachers used aural reinforcement, modelling, technique-based instruction and psychological prompts.

Savage (2012) focused upon the journey of a particular learner who had started formal guitar lessons but gave up after a short period of time. Although only a narrative of a single participant what is described in this article represents what may be informally occurring in homes around the globe. Savage describes how the pupil was able to slow-down instructional online videos to learn guitar parts, then using software add accompanying parts before publishing the work to forums on the internet for comment/critique. King (2012) describes this phenomenon from a pedagogical recording studio practice perspective that considers the roles and processes involved and how technology has empowered amateur musicians to harness the use of technology and publish music via the internet which from a historical perspective was beyond the financial means of many musicians. There are similarities with

\footnotetext{
2 https://bagpipelessons.com/

3 http://www.nytimes.com/2012/01/11/us/music-lessons-on-webcams-grow-inpopularity.html
} 
the narrative described by Savage (2012) and how technology (in this instance the 78rpm gramophone) enabled a generation of Jazz musicians to establish a musical craft, by repeating parts and playing along with particular recordings (see Katz, 2004, pp. 77-81).

Video conferencing (Cameron, 2010; Eberle \& Titze, 2003) and, specifically, Skype (Dammers, 2009; Pike \& Shoemaker, 2013) have been used elsewhere to deliver instrumental lessons, with some success. Dammers' work focused upon nine trumpet lessons between a tutor and teacher and specifically upon the feedback and progress made by the learner. Limitations of the study included issues around video delay (latency) and limited visual controls from a software perspective. Pike \& Shoemaker investigated the development of sight reading skills using online methods (for full description of approach see Pike \& Shoemaker, 2013) which also used a control group of students engaged in face-to-face lessons. The results suggested the online approach was a viable alternative to face-to-face lessons or at least a useful complement to a blended learning strategy involving a combination of in person and online lessons. This is particularly pertinent to this study since there are considerations here for teacher behaviour in online lessons that have yet to be fully investigated.

An opportunity arose to collaborate with North Yorkshire Music Action Zone and YouCanPlay to pilot the delivery of instrumental lessons using Skype in combination with a Roland VR-3EX, an AV Mixer with built-in USB port for Web Streaming and Recording, which offers 3 camera angles and good quality sound. It was anticipated that the addition of the AV mixer and the multiple camera angles might negate some of the issues described by Dammers (2009). This pilot lead to a roll-out across four geographical regions of the UK: Cornwall; Cumbria; Durham and Darlington; and East Riding of Yorkshire. $<2>$ Behaviour in music lessons 
Tuition in Western classical music has traditionally been based on a master-apprenticeship model, featuring 'the acquisition of experiential knowledge or skill; the use of demonstration and imitation; the master positioned as representative of the practice, with a high level of expertise; the apprenticeship as a source of identity for the learner; and the important and rather particular nature of the master-apprentice relationship' (Burwell, 2012, p. 43). In young beginners' lessons, the relationship between master and apprentice is particularly important, with high achieving children reporting their first teacher as being 'chatty' and 'friendly', and children who later gave up lessons reporting a teacher with more negative personal attributes. Interestingly, at this stage of learning, personal and musical attributes are conflated, with 'friendly' teachers being perceived by pupils as musical experts, and 'unfriendly' teachers being perceived as less competent. Later, when pupils are older and more advanced, these ideas seem to be separable, with young high achievers of secondary school age being able to place a teacher's musical abilities as of higher importance than their personal qualities (Sloboda \& Davidson, 1996). Instrumental lessons are usually conducted on a one-to-one basis, though lessons at the earlier stages of learning are frequently delivered in small groups, or more recently, whole classes (Hallam \& Creech, 2010). Hallam notes that 'comparisons of the effectiveness of group as opposed to individual lessons are inconclusive (Brandt, 1986)' and that 'A combination of individual and group tuition may be best. Studies of instrumental lessons show a wide range of approaches, something noted by Burwell (2012) as being a result not only of the individual characteristics of teachers and pupils, but also a result of the historical practices and current traditions of each instrumental specialism, and the relatively isolated position of many teachers, who may have few opportunities to discuss their practice with other teachers (though many conservatoires, exam boards, music services or hubs, and charitable organisations increasingly provide CPD for peripatetic teachers). 
These diverse behaviours in lessons have been studied previously, at various different levels of pupil age and expertise. Most observational studies find the most common pupil activity in lessons to be playing music, with considerable time devoted to teacher talk, with the balance of these activities seeming to vary according to the lesson activity (Hallam, 2006). Some of this teacher talk is devoted to praise, which increases motivation and effort in pupils, as long as it is honest. Kupers et al. investigated student-teacher interactions in instrumental lessons and the ways in which these changed levels of student autonomy, a key factor in students' motivation to continue with lessons (Kupers, van Dijk, van Geert, \& McPherson, 2015). Modelling behaviours are used, but relatively little, despite what Hallam describes as 'its potential effectiveness' (Hallam, 2006, p. 168). Scaffolding is provided for pupils by teachers, to enable pupils to learn in manageable tasks. The pace and intensity of lessons varies, but is seen as key to maintaining pupils' attention (Hallam, 2006).

The focus here will remain on children's instrumental lessons, rather than those of older or more advanced pupils (see Table 2). Creech (2012), for example, observes types of behaviour in instrumental lessons. She found that pupils played for 38 per cent of lesson time, either on their own or accompanied by the teacher; 29 per cent of lesson time was spent with the teacher talking to the pupil, 'either in a directive way, diagnosing pupil performance or providing feedback' (Creech, 2012, p. 392); a similar amount of time (28 per cent) involved the teacher providing 'scaffolding' behaviours for the pupils, such as playing along, or modelling behaviours; 9 per cent of the lesson time was spent questioning pupils; and 3 per cent of lesson time involved the pupil talking. In a much smaller study focused on gestures used in beginner instrumental teaching, Simones, Schroeder and Rodger (2015) also observed a range of behaviours in the lessons. They observed a similar level of time spent by teachers questioning pupils (6 per cent); but a much higher percentage of time spent modelling correct behaviours (40 per cent) and demonstrating (14 per cent). Creech's (2012) work linked the 
different behaviours she observed to a range of interpersonal interaction types, indicating that the relationship between teacher, pupil, and parent was related to the behaviours observed in lessons. She argues that successful teaching may be underpinned by a wide range of interpersonal behaviours, and advocates that teachers reflect on their own teaching to consider when each approach might be most appropriate, and when to implement change most effectively.

[insert table 2 here]

Previous studies on behaviour in music lessons focuses of face-to-face lessons, and previous studies of online delivery of instrumental lessons do not focus on behaviours in lessons. This article will compare behaviours observed in face-to-face and online music lessons in the current project, using some of the behaviour categories discussed above.

$<1>$ Aims and research questions

The overall aim of the project was to investigate how existing technology could be repurposed to provide peripatetic music lessons in remote rural communities. Within this, three smaller aims were devised:

1) To understand the technological challenges

2) To explore the pedagogical aspects

3) To compare the digital delivery with face-to-face lessons

$<$ 1 $>$ Methods

$<2>$ Participants

The project was delivered initially as a pilot study in North Yorkshire and subsequently as a roll-out study in Cornwall, Cumbria, Darlington and Durham, and the East Riding of Yorkshire. Similar research methods were used in the pilot and roll-out phases, though more 
detailed data were collected in relation to the pilot study than the roll-out study. Within the pilot study, a total of seven schools were involved in the project, all of which were located in geographically remote areas of North Yorkshire. They varied in size, with the smallest school having a total of twenty pupils and the largest a total of 232. Eight teachers were involved in the delivery of the lessons. All teachers were skilled and experienced and were working for the music service involved. The teachers taught a range of instruments, including clarinet, mixed woodwind (flute, saxophone and clarinet), violin, guitar, and trumpet.

In the roll-out study, five schools, four teachers, and 40 pupils were involved in the project. Violin, viola and percussion were taught to small groups of primary school pupils in Cumbria, Durham and Darlington, and East Riding. In Cornwall, a group of year 9 pupils were taught as a band, playing keyboard, vocals, drum kit, electric guitar, bass guitar and tambourine, and developing composition, songwriting and performance skills.

The data from the two studies will be considered within three main categories: the pilot study data (as this is more extensive than that for the roll-out); the primary school (KS2) pupils from the roll-out study (Cumbria, Durham and Darlington, and East Riding); and the year 9 group of pupils from Cornwall.

$<2>$ Materials and apparatus

Skype (version 7.2.0.103) was used for the video conferencing software on existing PCs located at the music centre and at each school. A Roland VR-3EX audio and video mixer was used in conjunction with three video cameras at selected locations (see table 1) to allow the evaluation of the most appropriate set-up. This enabled four different video channels to be used in conjunction with high quality microphones. Selected lessons were recorded using Camtasia screen casting software and a video camera (for back-up purposes).

$<2>$ Research schedule 
Before the pilot project began, participating teachers were interviewed via Skype (either with video or audio only). Pupils in the schools received two lessons per week over a period of seven weeks (i.e. a total of 14 lessons). In the first week of lesson delivery, the first online lessons with schools were captured. Similarly, lessons were captured in the final week of delivery. Four Face-to-face lessons involving either children from the participating schools or participating teachers were also captured to allow for comparison data. Interviews with peripatetic teachers and school staff involved with the project took place the week after the final lessons. School pupils and their parents completed questionnaires concerning their experiences and perceptions of the lessons received.

For the roll-out study, interviews with peripatetic teachers also took place before the start of the study. Pupils in the schools received between seven and 13 online lessons. Seven online lessons were recorded (one lesson with each group of pupils, with the exception of the two groups from the East Riding, where technical difficulties prevented this from happening). Final interviews were conducted with the peripatetic teachers. No pupil or parent questionnaires were collected.

$<1>$ Results

In the pilot study, teachers reported that the pupils concentrated well, and all the children reported enjoying the lessons 'a bit', 'quite a lot' or 'very much', with $63.4 \%$ in the latter category. Parents' reports of their children's enjoyment were slightly lower (though the difference was not significant in a paired samples t-test), but still very positive. The vast majority of pupils (87.8\%) reported practising between lessons. Parents were slightly less positive about the amounts of practice, but the majority reported their children doing some practice between lessons. It is worth noting that lessons took place twice a week, allowing less time for practice between lessons than in standard weekly music lessons. Parents gave 
positive feedback about children's progress, and most of the children (65.9\%) and many parents $(46.3 \%)$ wanted them to continue to learn their instruments 'quite a lot' or 'very much'. Face-to-face delivery was seen as preferable to online remote delivery by both children and their parents, but $39.0 \%$ of children and $29.2 \%$ of parents wanted the lessons to continue over the internet. The project did enable some children to receive a short period of music lessons who would otherwise not have had this opportunity: $73.1 \%$ of parent respondents would not have sought out instrumental lessons for their child if this opportunity had not been available; $76.9 \%$ of parents reported that they had never previously sought out instrumental tuition for their child; and $52 \%$ of parents reported that their children had not previously received instrumental tuition.

$<2>$ Behaviours in lessons: Comparisons with face-to-face lessons

The video data from both the pilot study and the roll-out study, which comprised four faceto-face lessons and 22 digitally-delivered lessons, were coded according to categories derived partly from existing studies in the area (Creech, 2012; Simones et al., 2015) but with the flexibility to allow the addition of other categories if prompted by the data. The approach was guided by the procedures outlined in Hseih and Shannon (2005) for a Directed Content Analysis. Once data were fully coded, we used the percentage coverage of the data to give an indication of the proportions of each lesson showing each kind of behaviour. As well as comparisons between face-to-face and digital lessons, data for the first and last digital lessons in the pilot study were considered separately, as it was thought that initial lessons may show different behaviours from lessons in which teacher and pupil are used to one another, to having lessons, and to the digital equipment.

$<2>$ Asking questions 
This category involved teachers asking questions of their pupils. These could be checking the understanding of technical information, such as note names in relation to pitch or rhythm, or asking for a child's opinion of a piece or their performance, or asking which piece they would like to play. Table 3 shows the mean and standard deviations of the face-to-face lessons, the digital lessons in the pilot study (initially separated into first and last digital lessons, and then presented as an overall mean), and the lessons in the roll-out study. The levels shown in all our lessons are considerably higher than those reported in the existing data above $(8.78 \%$ for Creech (2012) and 6.1\% for Simones, Schroeder and Roger (2015)). Within our sample (see Table 1), face-to-face lessons had similar levels to the digital lessons. Digital lessons in the pilot study showed teachers spending less time questioning pupils than in face-to-face lessons, while digital lessons in the roll-out study had levels of questioning that were comparable with our face-to-face lessons. The teacher in the band group lesson (working with older pupils on a more diverse array of instruments) spent the most time asking questions.

The standard deviations of these levels suggest some variation within our sample, and the raw data did suggest that particular teachers spent more time questioning their pupils than others. Overall, therefore, there is little evidence to suggest that the digital delivery of lessons has a particular impact on the amount of time teachers spend questioning pupils.

[insert table 3 here]

$<2>$ Giving advice, instructions or information, and Giving practise suggestions

The category 'Giving advice, instructions, information, or practise suggestions' involved teachers giving instructions to their pupils, such as 'So from now on, whenever you play a note, you always tongue it' (Clarinet teacher, face-to-face lesson); advice, such as 'just move your case, so you don't stand on it' (Violin teacher, face-to-face lesson); information, such as 
'five lines there, that's called the stave' (Violin teacher, digital lesson); or practise suggestions, such as 'The best thing to do F', when you're practising, is to do everything slowly, so that you're thinking 'where do my hands go, what does my bottom lip do, where do my teeth go' (Clarinet teacher, face-to-face lesson). This type of talk was considered as one large category, because of the potential for overlap between the subcategories above and the tendency to group similar ideas together in previous literature cited above. Table 4 shows the mean percentages of lessons where the teacher was giving advice, information instructions, or practice suggestions. These percentages were lower in digital lessons than in face-to-face lessons, and lowest in the roll-out study. In comparison with existing data for face-to-face lessons cited above, however, the overall levels of these categories for all our lessons were higher or comparable (Creech (2012)'s ‘Teacher talk' took up 29.14\% of lesson time, whereas Simones, Schroeder and Roger's (2015) categories of 'Giving advice or practice suggestions' and 'Giving information' totalled 31.5\%). The standard deviations within Table 2 do suggest variation over different lessons and teachers; this, and the variation between our data and existing research suggest little evidence for a consistent difference in the levels of this kind of teacher talk between face-to-face and digital lessons.

Some teachers, however, did comment in their final interviews that they felt the need to talk more in the Skype lessons than they usually would in face-to-face lessons. On average, the teachers from the pilot study rated the communication between themselves and the pupils as 9.38 out of 10 in face-to-face lessons (Standard Deviation $=0.74$ ), and as 7.75 in digitallydelivered lessons $($ Standard deviation $=1.67)$, a mean difference of 1.63 . Teachers from the pilot study rated their ability to explain what they wanted to pupils as 9.75 (Standard deviation $=0.71)$ out of 10 in face-to-face lessons and as $6.94($ Standard deviation $=1.15)$ in digitally-delivered lessons, a mean difference of 2.81 . These data suggest that this type of behaviour should be explored further in future research. 
[insert table 4 here]

$<2>$ Giving feedback (and praise)

Teachers frequently gave feedback on a pupil's performance, such as 'when you're on ... C, you use first finger, not third finger, so you never have fingers off the end of the guitar' (Guitar teacher, digital lesson). Some of the feedback was praise, such as 'Excellent' (Clarinet teacher, digital lesson). Levels of feedback or praise were similar in most of our lessons (see Table 5), though they were lower in the roll-out study than the Pilot study and face-to-face lessons. The levels were high in comparison with Simones, Schroeder and Rodger (2015), who reported levels of $4.4 \%$, and mostly similar to the category including feedback within Creech's (2012) work ('Teacher talk'; 29.14\%), though this category included other behaviours already considered above, and therefore it is likely that levels of feedback were lower in her data than in ours. Our data show considerable variation (as shown both in the mean levels and the standard deviation figures), and therefore do not provide evidence for any consistent difference in the levels of feedback or praise in face-to-face and digital lessons, particularly in light of the lower levels of feedback seen in the previous research discussed above.

[insert table 5 here]

$<2>$ Teacher demonstrating, modelling, accompanying, or listening/observing

Having examined some of the talk-based categories, we now come to the more practical categories of behaviour. These categories included Demonstrating, in which teachers demonstrated what they wished a child to do (for example, playing part of a piece while the child listened); Modelling, in which a teacher modelled what they wished a child to do (for example, playing their instrument as the child should while the child also played, or putting an instrument together while a child followed the same procedure); Accompanying (for 
example, playing a drone, a chord, or a specific accompaniment while a child played a melody); and Listening/observing (for example, listening to a child playing a piece). Within our data, there was considerable variation in the percentage of time spent on each activity (see Table 6). However, a multivariate ANOVA revealed that significantly more time was spent accompanying pupils in the face-to-face lessons than the digital lessons, even when discounting the data from the roll-out study $(\mathrm{F}(4,2)=15.53, \mathrm{p}<0.001)$ (see Figure 1). More time was spent listening or observing pupils in the digital lessons, but this did not reach significance. This was particularly high in the band group of the roll-out study. There was a large amount of demonstrating or modelling in the first digital lessons, which perhaps reflects the high proportion of time needed for pupils to learn to assemble unfamiliar instruments (e.g. clarinets) and to learn how to hold and play them, but again, this did not reach significance, perhaps because of the high variation in the data indicated by the standard deviation figures. The levels of demonstrating or modelling in the roll-out study were lower. The categories 'Demonstrating or modelling' and 'accompanying' equate to Creech's Teacher Scaffolding, and similar proportions of lesson time are spent on these activities here (in Creech's (2012) study, this was $27.73 \%$ ). In relation to Simones et al's work, the percentage of time spent modelling in our data is far lower than the $40 \%$ found in their study. It is unclear why this should be so, but it is perhaps notable that their data is based on piano lessons and ours on other instruments. Overall, there are few clear indications of consistent differences between face-to-face and digital lessons in relation to demonstrating or modelling and listening/observing. Levels of accompanying were significantly higher in face-to-face lessons than in digital lessons.

[insert table 6 here]

[insert figure 1 here] 
$<2>$ Pupils playing or singing

Overall, there was little difference between the percentage of time pupils spent playing or singing in face-to-face or digital lessons. The levels were lower than those found by Creech (38.05\%), but relatively consistent across conditions within our data. Within the roll-out study, levels of playing were higher in the Band group than in the other lessons. Overall, there is insufficient evidence to suggest any consistent difference between face-to-face and digital lessons in the percentages of lesson time spent playing or singing from these data.

[insert table 7]

$<1>$ Conclusions

This paper was intended to compare behaviours exhibited in face-to-face and online delivery of instrumental lessons, something that has not previously been explored explicitly. Overall, there appeared to be few consistent differences in behaviour in digital lessons in relation to face-to-face lessons, either from within our data or in contrast with figures published in existing literature. There seemed to be little evidence to suggest that the digital delivery of lessons has a particular impact on the percentage of lesson time teachers spend questioning pupils, giving feedback or praise, demonstrating or modelling, listening/observing, and pupils playing or singing. Although levels of teacher talk ('Giving advice, information, instructions, or practice suggestions') were not consistently different in face-to-face and digital lessons, teachers felt that they spent longer talking in digital lessons than in face-to-face lessons, and that communication was slightly more difficult over Skype. These findings warrant further investigation in future research. One potentially very important difference found in the data was in the levels of Accompanying in face-to-face and digital lessons. Accompanying was, as expected, more difficult and therefore less prevalent in digital lessons, with the data showing 
that levels of accompanying were significantly higher in face-to-face lessons than in digital lessons.

There appears to be considerable variation in the percentages of lesson time spent on each activity between the pilot study and the roll-out study, which might reflect the slightly different conditions of the lessons, but might simply reflect varying behaviour across a wider range of teachers. As noted above, a wide range of approaches are used within instrumental lessons due to the individual characteristics of pupils and teachers, the historical and current practices of different instrumental specialisms, and the relative isolation of many teachers (Burwell (2012).

$<2>$ Limitations:

In real-life studies of this kind, compromises are necessary between the ideal experimental design and the needs of the participants. In an ideal world, one might require an equal representation of a range of instruments and pupil ages in each location, as well as the same teachers delivering tuition in multiple geographical areas and in both face-to-face and online contexts, in order to provide fairer comparisons between groups. Although online technology does allow flexibility of teacher location, music tuition operates through geographicallysituated hubs, providing some restrictions of experimental design. Additionally, hubs, teachers and pupils need to be willing to participate, and therefore recruitment is guided by their availability. The diversity this provides is a disadvantage for the 'ideal' experimental design, but does provide a realistic insight into instrumental tuition in various rural parts of the UK, and highlights features of particular contexts that could not have been gleaned from a 'cleaner' design, and may be particularly pertinent to teachers involved in similar contexts elsewhere. They also provide further areas for future study. 
A further limitation is the length of the studies presented here. Although multiple lessons were provided for pupils, this potentially only represents a fraction of the length of each pupil's musical education. Longer studies of a year or more are necessary to tease out any potential relationship between the mode of delivery (face-to-face, online, or a blended approach), behaviours in lessons in those modes of delivery (both initially and as relationships between pupils and teachers develop), and subsequent pupil motivation and success in the longer term. Many factors may affect motivation and success over time, and these should be taken into account.

$<2>$ The future

As noted by previous studies and by the findings of this study, latency problems in online technologies such as Skype exist, affect behaviours in lessons (accompanying is very difficult and rarely attempted by teachers), and are difficult to solve. Solutions are being sought, with some success, though these will take time to filter through to budget-restricted schools. In the meantime, though technology may allow opportunities for music tuition that may otherwise be impossible or impractical because of geographical locations, it is notable that the current solution provides both connecting and isolating features: lessons can be had, but the development of the essential skills of accompanying are restricted, making pupils potentially 'lone' musicians. It will be interesting to observe how these trends develop over the coming years.

Acknowledgements: The team would like to acknowledge the funding provided by the Nesta Digital Research and Development award and the Arts Council England.

$<1>$ References 
Brandt, T. (1986). A review of research and literature concerned with private and class instruction in instrumental music. Journal of Band Research, 22(1), 48.

Burwell, K. (2012). Studio-Based Instrumental Learning. Farnham, UK: Ashgate.

Cameron, A. (2010). Instrumental Music Lessons Delivered via Video Conference to Remote Schools in Scotland - (V \& I Forum Pre-Conference). Paper presented at the Annual meeting of the ISME World Conference and Commission Seminars,, China Conservatory of Music (CC) and Chinese National Convention Centre (CNCC), Beijing, China. http://citation.allacademic.com/meta/p397831_index.html

Creech, A. (2012). Interpersonal behaviour in one-to-one instrumental lessons: An observational analysis. British Journal of Music Education, 29(03), 387-407. doi:doi:10.1017/S026505171200006X

Dammers, R. J. (2009). Utilizing Internet-Based Video-Conferencing for Instrumental Music Lessons. Update: Applications of Research in Music Education. doi: $10.1177 / 8755123309344159$

Eberle, K., \& Titze, I. (2003). Enhancing Voice Teaching With Technology. Journal of Singing, 59(3), 241.

Hallam, S. (2006). Music psychology in education. London :: Institute of Education, University of London.

Hallam, S., \& Creech, A. (2010). Learning to play an instrument. In S. Hallam \& A. Creech (Eds.), Music Education in the 21st Century in the United Kingdom: Achievements, analysis and aspirations (pp. 85-104). London: Institute of Education, University of London.

Hsieh, H.-F., \& Shannon, S. E. (2005). Three Approaches to Qualitative Content Analysis. Qualitative Health Research, 15(9), 1277-1288.

Katz, M. (2004). Capturing sound: How technology has changed music. (University of California Press, London).

Kruse, N. B., \& Veblen, K. K. (2012). Music teaching and learning online: Considering YouTube instructional videos. Journal of Music, Technology and Education, 5(1), 77 87. doi:10.1386/jmte.5.1.77_1

King, A. (2012). The Student Prince: Music-making with technology. The Oxford Handbook of Music Education, MacPherson \& Welch (eds.), 479-491, (New York: OUP, 2012)

Kupers, E., van Dijk, M., van Geert, P., \& McPherson, G. E. (2015). A mixed-methods approach to studying co-regulation of student autonomy through teacher-student interactions in music lessons. Psychology of Music, 43(3), 333-358. doi: $10.1177 / 0305735613503180$

Pike, P. D., \& Shoemaker, K. (2013). The effect of distance learning on acquisition of piano sight-reading skills. Journal of Music, Technology and Education, 6(2), 147-162. doi:10.1386/jmte.6.2.147_1

Savage, J. (2012). Tom's story: Developing music education with technology. Journal of Music, Technology and Education, 4(2-3), 217-226. doi:10.1386/jmte.4.2-3.217_1

Simones, L. L., Schroeder, F., \& Rodger, M. (2015). Categorizations of physical gesture in piano teaching: A preliminary enquiry. Psychology of Music, 43(1), 103-121. doi:10.1177/0305735613498918

Sloboda, J. A., \& Davidson, J. (1996). The young performing musician. In I. Deliège \& J. A. Sloboda (Eds.), Musical Beginnings: Origins and Development of Musical Competence (pp. 171-187). Oxford: Oxford University Press.

Waldron, J. (2012). Conceptual frameworks, theoretical models and the role of YouTube: Investigating informal music learning and teaching in online music community. Journal of Music, Technology and Education, 4(2-3), 189-200. doi:10.1386/jmte.4.23.189_1 
56

57

58

59 
Table 1: Rural characteristics of the five UK counties in the Connect Resound study

\begin{tabular}{|c|c|c|c|}
\hline County & $\begin{array}{l}\text { Area (size in } \\
\mathrm{Km}^{2} \text { ) }\end{array}$ & $\begin{array}{l}\text { Popular Density } \\
\left(\mathrm{Km}^{2}\right)\end{array}$ & Description \\
\hline Cornwall & 3563 & 150 & $\begin{array}{l}\text { The geographical shape and } \\
\text { position....dispersed and } \\
\text { sparsely populated } \\
\text { settlement pattern combined } \\
\text { with Cornwall's coastline } \\
\text { present issues of } \\
\text { accessibility and challenges } \\
\text { for equal provision of } \\
\text { services. }\end{array}$ \\
\hline Cumbria & 6767 & 73 & $\begin{array}{l}\text { More than } 50 \% \text { of Cumbria } \\
\text { is described as 'sparse' - } \\
\text { characterised by mainly } \\
\text { village, hamlet and isolated } \\
\text { dwellings. }\end{array}$ \\
\hline Darlington/Durham & 2225 & $250-499 / 100-249$ & $\begin{array}{l}\text { Both Durham and } \\
\text { Darlington contain } \\
\text { contrasting densely urban } \\
\text { and isolated sparse areas. } \\
61 \% \text { of the population of } \\
\text { County Durham live in rural } \\
\text { areas. }\end{array}$ \\
\hline $\begin{array}{l}\text { East Riding of } \\
\text { Yorkshire }\end{array}$ & 2432 & 140 & $\begin{array}{l}60 \% \text { of the population of } \\
\text { East Riding live in rural } \\
\text { areas. The majority of the } \\
\text { rural East Riding of } \\
\text { Yorkshire is classified as } \\
\text { 'less sparse rural' with over } \\
\text { half the population living in } \\
\text { dispersed rural } \\
\text { communities. }\end{array}$ \\
\hline North Yorkshire & 8608 & 132 & $\begin{array}{l}\text { The largest county in } \\
\text { England covering } 8608 \\
\text { square kilometres. Two of } \\
\text { the eleven areas designated } \\
\text { as national parks in England } \\
\text { are within this area. Large } \\
\text { areas of North Yorkshire are }\end{array}$ \\
\hline
\end{tabular}




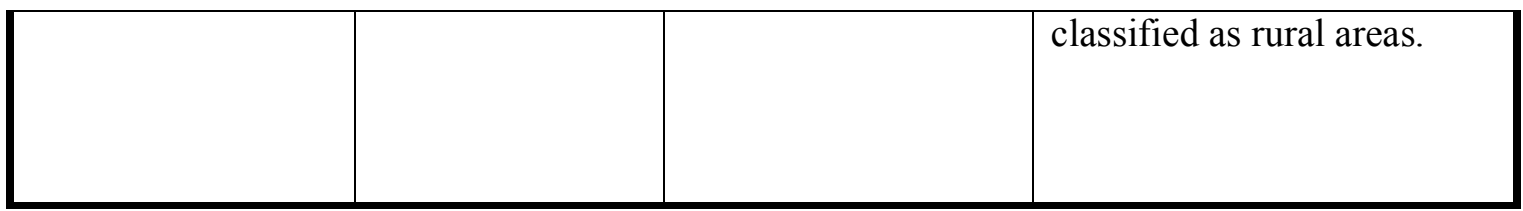

Table 2: Behaviours in instrumental lessons

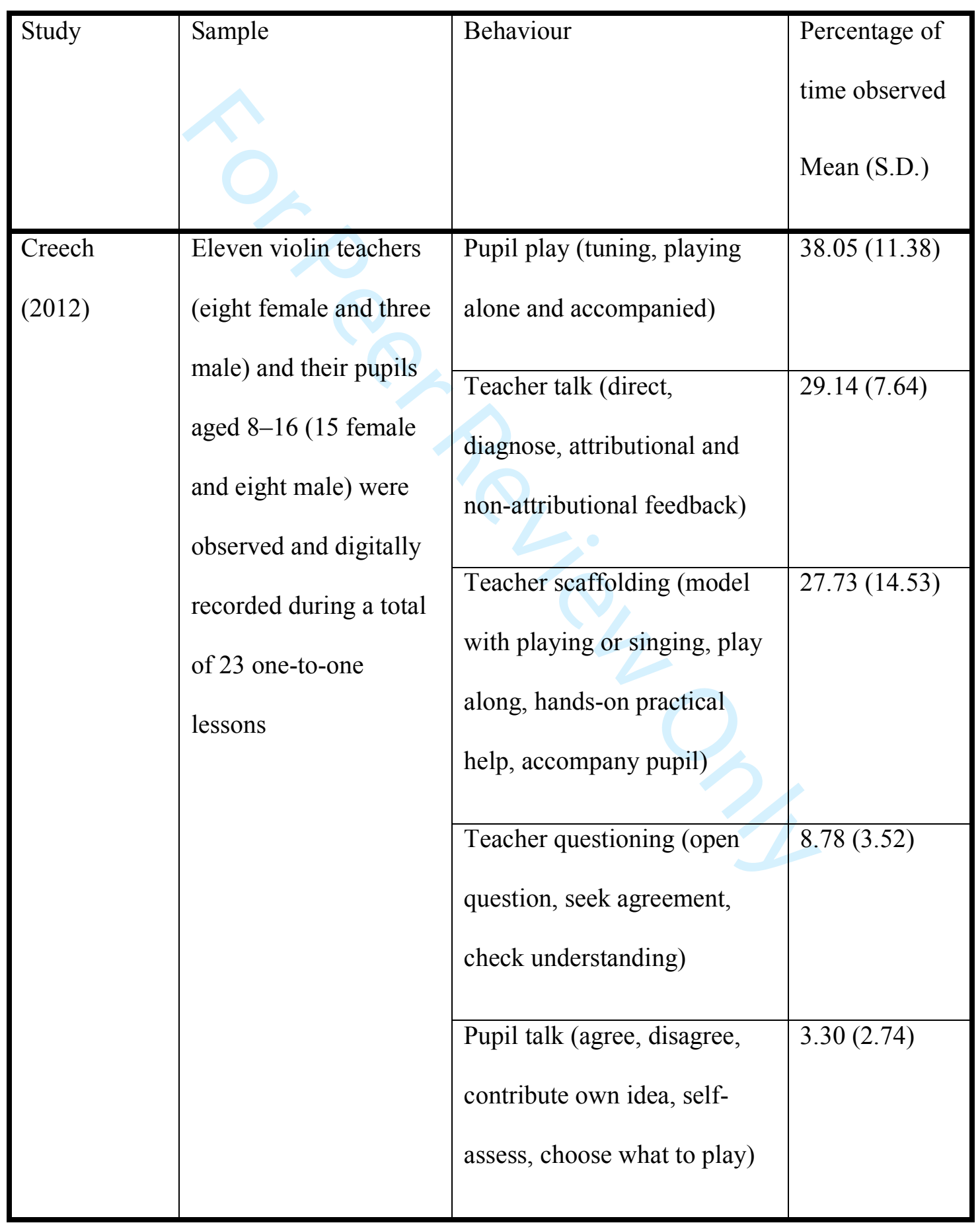




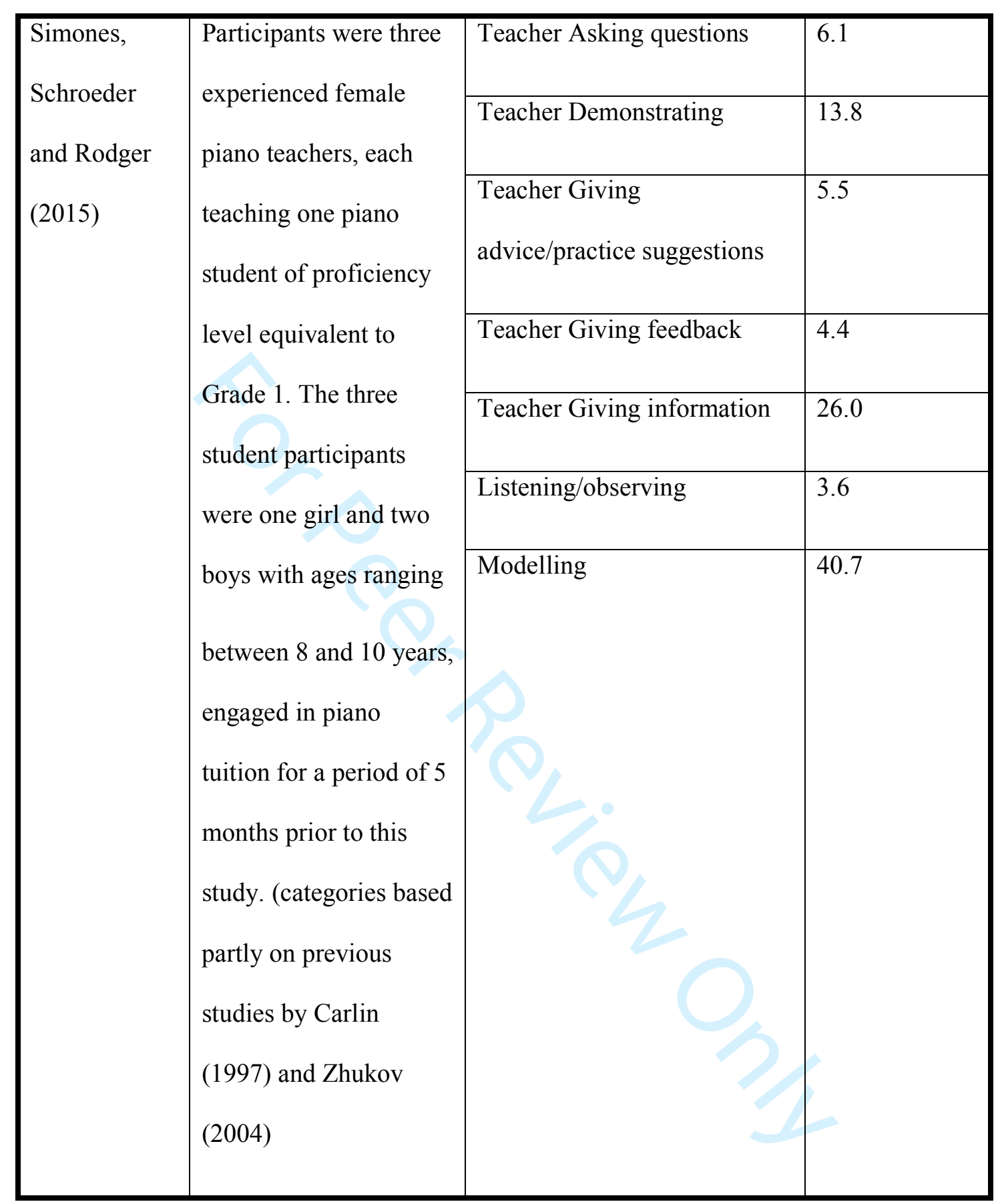

Table 3: Mean and standard deviations of the percentage of the lesson spent 'Asking questions'

\begin{tabular}{|l|l|l|l|}
\hline & Pilot study (North Yorkshire) & Roll-out study \\
\hline
\end{tabular}




\begin{tabular}{|c|c|c|c|c|c|c|}
\hline $\begin{array}{l}\text { Asking } \\
\text { Questions }\end{array}$ & $\begin{array}{l}\text { Face-to- } \\
\text { face } \\
\text { lessons } \\
(n=4)\end{array}$ & $\begin{array}{l}\text { First digital } \\
\text { lessons } \\
(n=8)\end{array}$ & $\begin{array}{l}\text { Last digital } \\
\text { lessons } \\
(n=7)\end{array}$ & $\begin{array}{l}\text { All digital } \\
\text { lessons } \\
(n=15)\end{array}$ & $\begin{array}{l}\text { Digital } \\
\text { lessons } \\
(n=6)\end{array}$ & $\begin{array}{l}\text { Band } \\
\text { group } \\
(n=1)\end{array}$ \\
\hline $\begin{array}{l}\text { Mean } \\
\text { (Standard } \\
\text { Deviation) }\end{array}$ & $\begin{array}{l}17.65 \\
(5.51)\end{array}$ & $\begin{array}{l}13.34 \\
(6.07)\end{array}$ & $11.69(5.38)$ & $\begin{array}{l}12.57 \\
(5.51)\end{array}$ & $\begin{array}{l}17.46 \\
(4.16)\end{array}$ & 27.79 \\
\hline
\end{tabular}

Table 4: Mean and standard deviations of the percentage of the lesson spent 'Giving advice, information or instructions' or 'Giving practice suggestions'

\begin{tabular}{|c|c|c|c|c|c|c|}
\hline & & Pilot study ( & Torth Yorksh & & Roll-ou & udy \\
\hline & $\begin{array}{l}\text { Face-to- } \\
\text { face lessons } \\
(\mathrm{n}=4)\end{array}$ & $\begin{array}{l}\text { First digital } \\
\text { lessons } \\
(\mathrm{n}=8)\end{array}$ & $\begin{array}{l}\text { Last digital } \\
\text { lessons } \\
(n=7)\end{array}$ & $\begin{array}{l}\text { All digital } \\
\text { lessons } \\
(n=15)\end{array}$ & $\begin{array}{l}\text { Digital } \\
\text { lessons } \\
(n=6)\end{array}$ & $\begin{array}{l}\text { Band } \\
\text { group } \\
(\mathrm{n}=1)\end{array}$ \\
\hline $\begin{array}{l}\text { Giving } \\
\text { advice, } \\
\text { information, } \\
\text { instructions or } \\
\text { practice } \\
\text { suggestions }\end{array}$ & $\begin{array}{l}55.78 \\
(7.10)\end{array}$ & $\begin{array}{l}50.67 \\
(12.18)\end{array}$ & $\begin{array}{l}37.88 \\
(8.14)\end{array}$ & $\begin{array}{l}44.70 \\
(12.09)\end{array}$ & $\begin{array}{l}21.07 \\
(6.14)\end{array}$ & 24.05 \\
\hline
\end{tabular}

Table 5: Mean and standard deviations of the percentage of the lesson spent 'Giving feedback' and 'Praise' 


\begin{tabular}{|c|c|c|c|c|c|c|}
\hline & & Pilot study & orth Yorkshi & & Roll-ou & udy \\
\hline & $\begin{array}{l}\text { Face-to- } \\
\text { face lessons } \\
(n=4)\end{array}$ & $\begin{array}{l}\text { First digital } \\
\text { lessons } \\
(n=8)\end{array}$ & $\begin{array}{l}\text { Last digital } \\
\text { lessons } \\
(\mathrm{n}=7)\end{array}$ & $\begin{array}{l}\text { All digital } \\
\text { lessons } \\
(n=15)\end{array}$ & $\begin{array}{l}\text { Digital } \\
\text { lessons } \\
(n=6)\end{array}$ & $\begin{array}{l}\text { Band } \\
\text { group } \\
(\mathrm{n}=1)\end{array}$ \\
\hline $\begin{array}{l}\text { Giving } \\
\text { feedback or } \\
\text { praise }\end{array}$ & $\begin{array}{l}26.98 \\
(9.86)\end{array}$ & $\begin{array}{l}24.24 \\
(10.44)\end{array}$ & $\begin{array}{l}18.59 \\
(6.67)\end{array}$ & $\begin{array}{l}21.60 \\
(9.06)\end{array}$ & $\begin{array}{l}13.32 \\
(5.65)\end{array}$ & 17.22 \\
\hline
\end{tabular}

Table 6: Mean and standard deviations of the percentage of the lesson spent 'Demonstrating', 'Modelling', 'Accompanying', and 'Listening/observing'

\begin{tabular}{|l|l|l|l|l|l|l|}
\hline & \multicolumn{5}{|l|}{ Pilot study (North Yorkshire) } & \multicolumn{2}{l|}{ Roll-out study } \\
\hline & Face-to- & First & Last & All digital & Digital & Band \\
& face & digital & digital & lessons & lessons & group \\
& lessons & lessons & lessons & $(\mathrm{n}=15)$ & $(\mathrm{n}=6)$ & $(\mathrm{n}=1)$ \\
$(\mathrm{n}=4)$ & $(\mathrm{n}=8)$ & $(\mathrm{n}=7)$ & & & \\
\hline Demonstrating or & 22.23 & 26.78 & 12.20 & 19.97 & $11.21(3.62)$ & 0.86 \\
\hline Accompanying & $(17.08)$ & $(20.65)$ & $(4.40)$ & $(16.67)$ & & \\
\hline Listening/observing & $10.14(4.29)$ & 0.35 & 1.86 & 1.06 & 0 & \\
& $(7.79)$ & $(4.64)$ & $(11.74)$ & $(9.46)$ & $(8.61)$ & \\
\hline
\end{tabular}


Figure 1: Time spent by teachers accompanying pupils in lessons with different modes of delivery

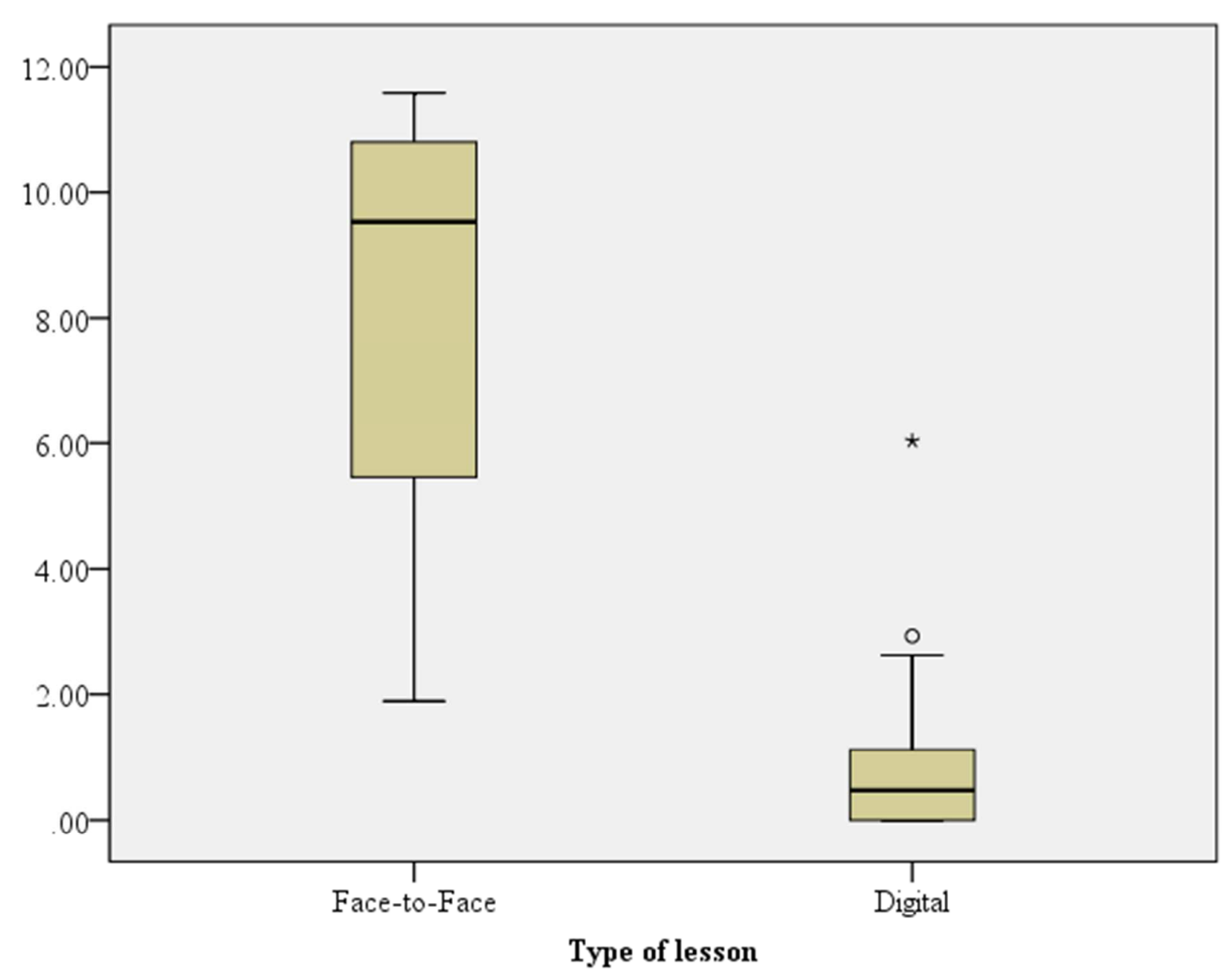

Table 7: Means and standard deviations of the percentage of the lesson in which 'Pupil plays' or 'Pupil sings'.

\begin{tabular}{|l|l|l|l|l|l|l|}
\hline & \multicolumn{3}{|l|}{ Pilot study (North Yorkshire) } & \multicolumn{2}{l|}{ Roll-out study } \\
\hline & Face-to- & First digital & Last digital & All digital & Digital & Band \\
& face lessons & lessons & lessons & lessons & lessons & group \\
& $(n=4)$ & $(n=8)$ & $(n=7)$ & $(n=15)$ & $(n=6)$ & $(n=1)$ \\
\hline Pupil plays & $20.92(8.40)$ & $16.21(7.66)$ & 30.74 & 22.99 & 10.55 & 31.12 \\
\hline
\end{tabular}




\begin{tabular}{|l|l|l|l|l|l|l|}
\hline & & & $(10.19)$ & $(11.41)$ & $(2.10)$ & \\
\hline Pupil sings & $2.83(2.73)$ & $0.27(0.33)$ & $2.83(2.73)$ & $0.12(0.26)$ & $0(0)$ & 0.34 \\
\hline
\end{tabular}

10

11

12

13

14

15

16

17

18

19

20

21

22

23

24

25

26

27

28

29

30

31

32

33

34

35

36

37

43

44

45

46

47

48

49

50

51

52

53

54

55

56

57

58

59

60

URL: http://mc.manuscriptcentral.com/cmue 